REVISTA DE DERECHO UNED, NÚM. 16, 2015

\title{
LA VIOLENCIA CONYUGAL EN EL CÓDIGO PENAL DE MARRUECOS
}

\author{
SPOUSAL ABUSE IN THE CRIMINAL CODE OF MOROCCO
}

\author{
DRISS JEDDI \\ Licenciado en Derecho \\ Doctorando del Departamento de Derecho Penal y Criminología \\ Universidad Nacional de Educación a Distancia
}

Resumen: La nueva Constitución marroquí de 2011 establece la igualdad entre hombres y mujeres. Así mismo, el Reino de Marruecos ha ratificado la Convención sobre la eliminación de todas las formas de discriminación contra la mujer y levantado las reservas que había hecho en un principio. Tras la reforma del Código penal por la Ley 24/03 se ha añadido a los esposos como autores y víctimas del maltrato físico durante el matrimonio dando lugar a tipos agravados según las consecuencias de ese maltrato. Esto ha supuesto de hecho un refuerzo de la protección de las mujeres frente a los malos tratos físicos en el ámbito conyugal dado que ellas son víctimas en la mayoría de los casos. En este trabajo se expone la tipología de la violencia conyugal y sus consecuencias jurídicas.

Abstract: The new Moroccan Constitution of 2011 establishes the equality between men and women. Likewise, the Kingdom of Morocco has ratified the Convention on the elimination of all forms of discrimination against women and has removed the reservations it had at first. Following the reform of the Criminal Code by Law 24/03, husbands have been added as perpetrators and victims of physical abuse during marriage, leading to aggravated offenses depending upon the consequences of such abuse. This has in fact led to a strengthening of the protection of women against physical abuse in the conjugal scope because they are victims in most of the cases. This paper presents the typology of spousal violence and its legal consequences. 
Palabras clave: malos tratos conyugales - Código penal de Marruecos.

Key words: spousal abuse - Criminal Code of Morocco.

Recepción original: 24/02/2015

Aceptación original: 27/03/2015

\section{CONSIDERACIONES PREVIAS}

El Reino de Marruecos firmó el 8 de enero de 1986 ratificó la Convención contra la tortura y otros tratos o penas crueles, inhumanas o degradantes (CAT), cuyas disposiciones se aplican en el marco de la violencia de género, así como el 21 de junio de 1993 la Convención sobre la eliminación de todas las formas de discriminación contra la mujer (CEDAW) levantando el 8 de abril de 2011 las reservas hechas a los artículos 9.2 y 16 y manteniendo las declaraciones en cuanto a los artículos 2 y $15.4^{1}$.

La nueva Constitución marroquí, promulgada el 1 de julio de 2011, en su art. $19^{2}$ consagra la igualdad entre mujeres y hombres y la obli-

${ }^{1}$ Artículo 2:

«El Gobierno del Reino de Marruecos expresa su voluntad de aplicar lo dispuesto en este artículo siempre y cuando:

- No afecte a las disposiciones constitucionales por las que se regula la sucesión al trono del Reino de Marruecos;

- No contravenga las disposiciones de la sharia islámica. Cabe señalar que determinadas disposiciones del Código Civil de Marruecos por las que se otorgan a la mujer derechos que difieren de los otorgados a los hombres no pueden conculcarse ni derogarse, ya que se fundan en la sharia islámica, uno de cuyos objetivos es establecer un equilibrio entre los cónyuges con el fin de preservar la solidez de las relaciones familiares.»

Artículo 15, párrafo 4:

«El Gobierno del Reino de Marruecos declara que solo puede considerarse obligado por lo dispuesto en este párrafo, en particular lo relativo al derecho de la mujer a elegir su residencia y domicilio, en la medida en que no sea incompatible con los artículos 34 y 36 del Código Civil de Marruecos.»

${ }^{2}$ Art. 19 Constitución Marruecos: «El hombre y la mujer disfrutan, en igualdad, de los derechos y libertades de carácter civil, político, económico, social cultural y medioambiental, enunciados en el presente título y en las otras disposiciones de la Constitución, así como en las convenciones y pactos internacionales debidamente ratificados por el Reino y esto en el respeto de las disposiciones de la Constitución, de las constantes y de las leyes del Reino. El Estado marroquí trabaja para la realización de la paridad entre hombres y mujeres. Se crea, a este efecto, una Autoridad para la paridad y la lucha contra todas las formas de discriminación.»

Art. 20 Constitución Marruecos: «El derecho a la vida es el primer derecho de todo ser humano. La ley protege este derecho.» 


\section{La violencia conyugal en el Código Penal de Marruecos}

gación del Estado de velar por la efectividad de la paridad. En el año 2004 se realizó una reforma del Código de la Familia (CFM) o Moudawana ${ }^{3}$, en vigor desde el 3 de febrero de 2004, con el objetivo de ampliar los derechos de la mujer así como establecer la igualdad entre los cónyuges respecto de las obligaciones y los deberes mutuos ${ }^{4}$. Esta evolución legislativa también se ha producido en otros ámbitos como el Código de Procedimiento Penal (CPPM) ${ }^{5}$, el Código de Procedimien-

Art.22 Constitución Marruecos: «No se puede atentar a la integridad física o moral de ninguna persona, en ninguna circunstancia ni por ninguna persona pública o privada.

Nadie puede infligir a otra persona, bajo ningún pretexto, tratos crueles, inhumanos, degradantes o que atenten a la dignidad.

La práctica de la tortura, bajo todas sus formas y por cualquiera, es un crimen castigado por la ley.»

${ }^{3}$ La modificación de la Moudawana tomó impulso con el Plan Nacional para la Integración de la Mujer en el Desarrollo en 1998 (PANIFD) que fue el detonante de dos manifestaciones simultáneas en 2000 donde se oponían las feministas contra los islamistas. Dio lugar a una movilización sin precedente del movimiento de mujeres progresista. Para satisfacer las reivindicaciones de ambos lados, el poder impulsó un «feminismo islámico de Estado» mediante las reformas de 2004-2006. El debate social fue tan intenso que el Rey presentó la reforma del Código de la Familia como uno de los pilares de la transición democrática que pretendía promover. Este Código de 2004, trajo novedades como elevar la edad para contraer matrimonio a los 18 años para el hombre y la mujer (art. 19 CFM), establecer que la familia está bajo la dirección de ambos cónyuges (art.4), igualar los derechos y deberes recíprocos entre los cónyuges (art.51 CFM), dar a la mujer el derecho de poner fin a la relación matrimonial (arts. 94 a 98CFM), etc.

EL BACHIRI, LEÏLA: «Place de la femme dans le droit musulman à travers l'exemple du Code de la famille du Maroc: la Mudawana entre tradition et modernité», en Les islams, n²6, printemps-été 2011, ed. Reliures, Bélgica.

${ }^{4}$ Art.51 CFM: «Los derechos y deberes mutuos entre cónyuges serán los siguientes:

1. la convivencia legal, que implica las buenas relaciones conyugales, la justicia, la igualdad de trato entre esposas en caso de poligamia, la pureza y fidelidad mutuas, la virtud y la preservación del honor y el linaje;

2. las buenas relaciones de la vida en común, el respeto, el afecto y la atención mutuos, así como la salvaguarda de los intereses familiares;

3. la responsabilidad de la esposa, junto con el marido, de la administración de los asuntos del hogar y la protección de los hijos;

4. la decisión consensuada en lo que respecta a la administración de los asuntos de familia, los hijos y la planificación familiar;

5. las buenas relaciones de cada uno de ellos con los padres del otro y los familiares que suponen un impedimento al matrimonio, respetándolos, visitándoles y recibiéndoles con arreglo a su conveniencia;

6) los derechos sucesorios mutuos.

Art. 52 CFM: «Cuando uno de los cónyuges persista en el incumplimiento de las obligaciones señaladas en el artículo anterior, la otra parte podrá reclamar la ejecución de las obligaciones que le incumban o recurrir al procedimiento de discordia previsto en los artículos 94 a 97 ».

${ }^{5}$ Según el Código de Procedimiento Penal antes de la modificación de su art. 336, la mujer marroquí no tenía el derecho de personarse como parte civil en un pleito sin 


\section{DRISS JEDDI HAOUKICH}

to Civil (CPCM) $)^{6}$, el Código del Trabajo (CTM)7. En esta línea el Código penal también se ha actualizado con el fin de garantizar la igualdad.

En el Reino de Marruecos no existe una legislación específica que criminalice la violencia de género ${ }^{8}$. Sin embargo, tras la reforma operada en el Código penal por la Ley $24.03^{9}$, de 11 de noviembre de 2003, este ha evolucionado en la misma dirección que la mayoría de las legislaciones occidentales aprobando disposiciones relativas a la protección de la mujer contra la violencia de los hombres. Estas modificaciones fueron la consecuencia de la proliferación de las agresiones sobre las mujeres ${ }^{10}$ que se castigaban de forma más leve como simples lesiones agravadas cuando existía una relación de parentesco. Hay que señalar que la modificación de la ley penal se debió a la lucha activa de la sociedad civil y de las asociaciones de mujeres ${ }^{11}$.

En el Código penal marroquí se tipifica el delito la violación ${ }^{12}$, en la que solo se considera como posible víctima a la mujer, construyendo un supuesto agravado en atención a algunas características personales de las víctimas; se introduce el delito de agresiones o lesiones entre cónyuges $^{13}$, reafirmando la igualdad entre los dos miembros del matrimonio; se ha incluido en la lista de los delitos que pueden dar lugar a la

autorización del tribunal. Tras la modificación la mujer ya no necesita esta autorización si ella quiere personarse como parte civil contra su marido.

${ }^{6}$ Art.179 bis CPCM: la demanda de la pensión alimenticia del cónyuge se resuelve de forma inmediata y se ejecuta a pesar de recurso interpuesto.

${ }^{7}$ El Código de trabajo, adoptado en 2004, prohíbe, entre otras, la discriminación basada en el sexo o la situación matrimonial, afirmando expresamente que la mujer puede firmar un contrato de trabajo y que, casada o no, puede afiliarse a un sindicato profesional así como participar en su administración y gestión (art.9). El art. 346 prohíbe toda discriminación en el salario entre los dos sexos para un trabajo de igual valor.

${ }^{8}$ Desde 2006 el Gobierno marroquí declara que va a promulgar una ley relacionada con la violencia de género, sin embargo no parece que se estén produciendo avances notables.

${ }^{9}$ BOE del Reino de Marruecos de 5 de Enero de 2004.

${ }^{10} \mathrm{El}$ total de los delitos de violencia contra la mujer que llegaron a los tribunales marroquíes entre 2000 y 2009 fueron 200.931 (7.669 casos en 2000 y 16.160 en 2009), en Revista de asuntos penales, Ministerio de justicia y Libertades, núm. 1, diciembre de 2011, pág. 65

${ }^{11}$ A modo de ejemplo, Asociación marroquí para luchar contra la violencia sobre la mujer, Asociación marroquí de planificación familiar, Asociación marroquí de defensa de los derechos de la mujer.

${ }^{12}$ La violación es un crimen contra la moralidad y no un crimen contra la libertad $\mathrm{o}$ indemnidad sexual.

${ }^{13}$ Hasta la reforma del Código pena por Ley 24.03, que añadió a la lista de víctimas a los cónyuges, estas agresiones y lesiones físicas se calificaban como delitos de lesiones agravadas por la relación de parentesco. 
reincidencia los delitos cometidos contra el cónyuge ${ }^{14}$. Así se aplicarán las normas de la reincidencia al condenado por sentencia firme por un acto de violencia contra su otro cónyuge, si antes de que transcurra el plazo de cinco años después de haber cumplido su condena o de la prescripción de esta, comete otro delito contra el mismo cónyuge.

\section{DATOS ESTADÍSTICOS DE VIOLENCIA CONTRA LAS MUJERES EN MARRUECOS}

Tipos de violencia cometidos contra la mujer en Marruecos $(2010)^{15}$

\begin{tabular}{lc}
\hline \multicolumn{1}{c}{ Tipo de violencia cometida contra la mujer } & Número de casos \\
\hline Violencia causa de incapacidad inferior a 20 días & 7.350 \\
\hline Abandono de familia & 4.068 \\
\hline Violencia causa de incapacidad superior a 20 días & 3.216 \\
\hline Atentado al pudor con violencia & 886 \\
\hline Violación & 841 \\
\hline Violación con pérdida de virginidad & 753 \\
\hline Ocultación de mujer casada & 311 \\
\hline Abuso sexual, con ánimo de lucro & 183 \\
\hline Lesiones que causan incapacidad permanente & 73 \\
\hline Homicidio intencionado & 52 \\
\hline Lesiones imprudentes que causan la muerte & 40 \\
\hline Aborto & 21 \\
\hline Expulsión del domicilio & 21 \\
\hline Abuso sexual en una red organizada & 15 \\
\hline Secuestro de mujer casada & 4 \\
\hline Turismo sexual pata los extranjeros & 4 \\
\hline Envenenamiento & 3 \\
\hline Red de tráfico de mujeres & 1 \\
\hline Aborto que causa la muerte & 0 \\
\hline \multicolumn{1}{c}{ Total general } & $\mathbf{1 7 . 8 4 2}$
\end{tabular}

${ }^{14}$ Art.158 CPM: «Se considera que constituyen el mismo delito para determinar la reincidencia, las infracciones agrupadas en cada párrafo de los apartados siguientes: .... 5. . $^{\circ}$ Todos los delitos cometidos por un cónyuge contra el otro».

15 «La justicia Penal en Marruecos, números y datos», en Revista de Asuntos Penales, n. ${ }^{\circ}$ 2, ed. Ministerio de Justicia y Libertades, octubre de 2012, pág. 281.

(C) UNED. Revista de Derecho UNED, núm. 16, 2015 


\section{DRISS JEDDI HAOUKICH}

El fenómeno de violencia física contra la mujer está muy extendido en Marruecos, se ha registrado 10.731 casos durante 2010, lo que representa una tasa del $60 \%$ del total de los casos de violencia presentados ante los tribunales (violencia en general). En el mismo año hubo 3.019 casos de violencia sexual, con una tasa del $16.9 \%$ sobre el total de los casos de violencia presentados ante los tribunales marroquíes ${ }^{16}$.

Distribución por Partido judicial de casos de violencia contra la mujer en Marruecos (2010) $)^{17}$

\begin{tabular}{|c|c|}
\hline Partido judicial & Número de casos \\
\hline Rabat & 1.105 \\
\hline Casablanca & 1.846 \\
\hline Kenitra & 1.563 \\
\hline Fez & 1.162 \\
\hline Taza & 435 \\
\hline Marrakech & 1.939 \\
\hline Asafi & 1.193 \\
\hline Meknes & 1.600 \\
\hline Rachidia & 113 \\
\hline Tánger & 1.301 \\
\hline Tetuán & 269 \\
\hline Jadida & 1.403 \\
\hline Beni Mallal & 786 \\
\hline Oujda & 550 \\
\hline Nador & 186 \\
\hline Husseima & 106 \\
\hline Agadir & 866 \\
\hline Ouarzazat & 132 \\
\hline Layoune & 395 \\
\hline Khouribga & 381 \\
\hline Settat & 514 \\
\hline
\end{tabular}

\section{Total general}

17.842

${ }^{16}$ En Marruecos, todas las denuncias en materia penal deben presentarse ante la comisaria o la policía, o directamente ante el Procurador del Rey (Ministerio fiscal). Este último es el encargado de la investigación de manera que dicta la persecución si ve indicios delictivos, o dicta el archivo de la causa si no los hay.

17 «La justicia Penal en Marruecos, números y datos», ob.cit., pág. 280 


\section{La violencia conyugal en el Código Penal de Marruecos}

A Partir de las estadísticas del año 2010 publicadas por el Ministerio de Justicia y Libertades, se puede apreciar que la tasa de violencia contra la mujer es más elevada en Marrakech, Casablanca, Kenitra, Meknes, Jadida y Tánger, sin embargo oscila entre una tasa media y débil en el resto de partidos judiciales.

\section{LOS MALOS TRATOS FÍSICOS ENTRE CÓNYUGES}

En la redacción anterior a la modificación del Código penal marroquí por Ley 24.03 no se mencionaba al cónyuge como víctima de golpes o lesiones ${ }^{18}$. Tras su modificación el art. 404 CPM tiene la siguiente redacción:

"Cualquiera que voluntariamente golpee o cause lesiones a uno de sus ascendientes, a su tutor [kafil] o a su cónyuge, es castigado:

$1 .^{\circ}$ En los casos y según las distinciones previstas en los artículos $400^{19}$ y $401^{20}$, con el doble de las penas previstas en dichos artículos.

2. ${ }^{\circ}$ En el caso previsto en el primer párrafo del artículo $402^{21}$, con reclusión de diez a veinte años; en el caso previsto en el segundo párrafo, con reclusión de veinte a treinta años;

${ }^{18}$ Art. 404 CPM (redacción anterior a la Ley 24.03): «Cualquiera que voluntariamente golpee o cause lesiones a uno de sus ascendientes, será castigado de la siguiente forma:

1. ${ }^{\circ}$ En los casos previstos en los arts. 400 y 401, con el doble de la pena dictada en cada caso, según las circunstancias indicadas.

2. ${ }^{\circ}$ En el caso previsto en el artículo 402 apartado 1, a la pena de prisión de diez a veinte años; en el caso previsto en el apartado 2 a prisión de veinte a treinta años;

3. ${ }^{\circ}$ En el caso contemplado en el apartado 1 del artículo 403, con prisión de veinte a treinta años; en el caso previsto en el apartado 2, a cadena perpetua.»

${ }^{19}$ Art. 400 CPM: «Cualquiera que, voluntariamente, cause lesiones o golpee a otra persona o cometa cualesquiera otras violencias o hechos, que no hayan causado ni enfermedad, ni incapacidad, o que hayan causado una enfermedad o incapacidad para el trabajo personal que no exceda de veinte días, es castigado con prisión de un mes a un año y multa de 200 a 500 dirhams o con una de estas dos penas solamente.

Cuando haya premeditación o alevosía o uso de un arma, la pena es prisión de seis meses a dos años y multa de 200 a 1.000 dirhams.»

${ }^{20}$ Art. 401 CPM: «Cuando de las lesiones o los golpes u otras violencias o agresiones resulte una incapacidad superior a veinte días, la pena es de prisión de unos a tres años y multa de 200 a 1.000 dirhams

Cuando haya premeditación o alevosía o se use un arma, la pena es prisión de dos a cinco años y multa de 250 a 2.000 dirhams.

Al culpable se le puede imponer, además, entre cinco años como mínimo y diez años como máximo la interdicción de uno o varios de los derechos mencionados en el artículo 40 de este código y la prohibición de residencia.»

${ }^{21}$ Art. 402 CPM: «Cuando de las lesiones o los golpes u otras violencias o agresiones resulte una mutilación, amputación o privación del uso de un miembro, ceguera, 


\section{DRISS JEDDI HAOUKICH}

$3^{\circ}$ En el caso previsto en el primer párrafo del artículo $403^{22}$, con reclusión de veinte a treinta años y en el caso previsto en el segundo párrafo, con cadena perpetua.»

El art. 404 CPM contiene varios tipos agravados de lesiones en base a la relación de parentesco que une al autor con la víctima, enumerando expresamente la relación conyugal legalmente establecida. La remisión a los arts. 400 a 403 CPM sirve para modular las penas en proporción con el daño causado por las agresiones dolosas.

El legislador ha hecho hincapié en los casos de lesiones entre los cónyuges, ya que no es la violencia de un hombre contra una mujer o una mujer contra un hombre en cualquier circunstancia. Ha querido penar más gravemente las agresiones violentas entre dos personas casadas.

En el Código penal marroquí no existe una definición de lo que se debe calificar como lesión, como lo hace el Código penal español, por lo que habrá que entender que el resultado es un menoscabo de la integridad corporal o la salud física de la víctima ${ }^{23}$. Tampoco determina los medios o instrumentos con los que se comete la agresión por lo que cualquier medio es suficiente. En cuanto al método o modo de comisión se deduce que debe ser violento. Este tipo básico es muy amplio y su aplicación es residual para los casos en los que no concurren las circunstancias más específicas de los arts. 400 a 403 CPM cuando esos golpes o lesiones ocasionan enfermedad, incapacidad temporal, mutilación, amputación o privación del uso de un miembro, ceguera, pérdida de un ojo, enfermedad permanente o la muerte involuntaria.

Es una lamentable realidad constatar que en Marruecos, como en general en todos los países del mundo, la gran mayoría de las víctimas de violencia física conyugal son las mujeres. Sin embargo, el legislador marroquí ha establecido la igualdad en el castigo de las lesiones entre los cónyuges con el objetivo de no permitir la violencia entre dos personas casadas, con independencia de se trate de violencias de hombre contra mujer o de mujer contra hombre.

pérdida de un ojo o cualesquiera otras enfermedades permanentes, la pena es la reclusión de cinco a diez años.

Cuando haya premeditación o alevosía o se use un arma, la pena es la reclusión de diez a veinte años.»

${ }^{22}$ Art. 403 CPM: «Cuando las lesiones o los golpes u otras violencias o agresiones se hayan realizado voluntariamente pero sin la intención de causar la muerte, y sin embargo la hayan causado, la pena es reclusión de diez a veinte años.

Cuando haya premeditación o alevosía o se use un arma, la pena es cadena perpetua.»

${ }^{23}$ AHMED EL KAMLICHI: Derecho Penal. Parte especial, edit. El Maarif, Rabat 1986. pág. 111 y ss. 


\section{La violencia conyugal en el Código Penal de Marruecos}

Algunos ejemplos para determinar cuáles son las actividades incluidas en este delito de agresiones físicas en el ámbito conyugal ${ }^{24}$ :

a) Paliza: es toda la presión, golpe o fricción sobre el cuerpo de la víctima que produzca por el impacto un traumatismo, enrojecimiento de la piel, hinchazón, etc. Puede realizarse golpeando con la mano o con el pie o por medio de cualquier instrumento como puede ser un palo, cinturón o cable, también presionando el cuello de la víctima ${ }^{25}$. Cuanto más visible sea el efecto exterior de la paliza habrá más facilidades de probar el hecho delictivo.

b) Lesión: la acción violenta deja una marca en el cuerpo de la víctima. Se puede apreciar a simple vista, como disección de la piel, quemaduras, rotura de huesos, o necesitar una radiografía para diagnosticarla como una hemorragia interna o daños en el hígado ${ }^{26}$.

c) Violencia: causa sufrimiento a la víctima aún sin golpearla o causarle una lesión, como tirarle del pelo, atarla con una cuerda, etc.

Además de la violencia física la mujer puede sufrir otros tipos de violencia, como la violencia verbal (insultos, humillaciones), las críticas distorsivas (llamarla gorda, analfabeta), el abuso del poder (incitar la mujer a suicidarse, controlar su tiempo libre), las faltas de respeto (ausencia de dialogo, rechazar comer juntos), el abuso de confianza (mentiras), el control económico (privar de dinero, no hacer la compra $)^{27}$. Esta violencia que tiene una vertiente más psicológica que física no está penada en la ley marroquí como constitutiva de una infracción penal de violencia contra la mujer.

\section{III.A. Modalidades delictivas}

Acorde al art. 404 CPM se puede distinguir por el resultado cinco tipos de lesiones o agresiones de menos a más graves:

${ }^{24}$ ABDELWAHID EL ALAMI MACHICHI: Explicación de la Ley penal marroquí. Parte especial, edit. El Najah, Casablanca 2009, págs. 306 y 307.

${ }^{25}$ FADIL MOHAMED: Explicación de la ley de las penas. Parte especial pag.406. Citado por EL ALAMI MACHICHI: ob., cit., pág. 306.

${ }^{26}$ ABOU EL MAATI HAFID / ABOU EL FOUTOUH: Explicación de la Ley penal marroquí. Parte especial, edit. El Najah, Casablanca 1983, pág.135

${ }^{27}$ LATIFA JOUHIR: Les violences conjugales au Maroc. Etude sociologique, Centre d'écoute et orientation juridique et de soutien psychologique pour femme victime, Casablanca, 2003, pág. 11. 


\section{DRISS JEDDI HAOUKICH}

a) Lesiones o agresiones que no causan enfermedad o incapacidad ${ }^{28}$ (en relación con el primer inciso del primer párrafo del art. 400 CPM)

b) Lesiones o agresiones que causan enfermedad o incapacidad con una baja médica inferior a 20 días (en relación con el segundo inciso del primer párrafo del art. 400 CPM)

c) Lesiones o agresiones que causan incapacidad con una baja médica superior a 20 días (en relación con el primer párrafo del art. $401 \mathrm{CPM}$ ).

d) Lesiones o agresiones que causan mutilación, amputación o privación del uso de un miembro, ceguera, pérdida de un ojo o enfermedad permanente (en relación con el primer párrafo del art. 402 CPM).

e) Lesiones o agresiones voluntarias que causan involuntariamente el fallecimiento del lesionado (en relación con el primer párrafo del art. 403 CPM).

A pesar de la diferente gravedad del resultado el Código no hace distinciones entre los casos a) y b) a los efectos penológicos. En el resto de los casos la gravedad de la pena se modula según el resultado. Y teniendo en cuenta las penas previstas, los supuestos a) y b) corresponden a la categoría ${ }^{29}$ de delitos de policía, el supuesto c) a la de delito correccional y a la de crímenes los supuestos d) y e).

En todas las infracciones existe una previsión de agravación de la pena cuando concurre la premeditación o la alevosía, sin que lleguen a variar las categorías de las infracciones cometidas. Tampoco variará esta categoría cuando se aprecie una causa de atenuación de la pena o de reincidencia del condenado ${ }^{30}$. Sin embargo, la categoría puede mo-

${ }^{28}$ Hasta la entrada en vigor de la Ley 10/42 de Jueces de proximidad, que organiza la jurisdicción marroquí en Tribunales de Primera Instancia, Tribunales de Apelación, y Tribunal Supremo, las lesiones leves eran competencia de Tribunales de Municipio o de Distrito (equivalentes a los Juzgados de Paz españoles) creados por la Ley 393.74.1, de 15 de Julio de 1974, y suprimidos por la Ley 10/42.

${ }^{29}$ Art. 111 CPM: «Las infracciones son calificadas como crimen, delito correccional, delito de policía o contravención:

La infracción que la ley castiga con una de las penas previstas en el artículo 16 es un crimen;

La infracción que la ley castiga con una pena de prisión cuyo máximo está fijado en más de dos años es un delito correccional;

La infracción que la ley castiga con una pena de prisión cuyo máximo está fijado en dos años o menos de dos años, o con una multa de más de 200 dirhams es un delito de policía.

La infracción que la ley castiga con una de las penas previstas en el artículo 18 es una contravención.»

${ }^{30}$ Art. 112 CPM: «La categoría de la infracción no se modifica cuando, como consecuencia de una causa de atenuación de la pena o del estado de reincidencia del 


\section{La violencia conyugal en el Código Penal de Marruecos}

dificarse cuando se aprecien circunstancias agravantes en los hechos y se imponga una pena que pertenezca a otra categoría de infracción ${ }^{31}$. Estas variaciones son importantes respecto al cumplimiento de la condena si una pena de prisión ${ }^{32}$ se convierte en una pena de reclusión ${ }^{33}$.

En cualquier caso debe existir una relación de causalidad entre la acción típica y el resultado causado ${ }^{34}$. Si no se produce el resultado delictivo la conducta es atípica ${ }^{35}$, salvo que se trate de una tentativa de crimen castigada con la misma pena que el crimen consumado ${ }^{36}$.

La dificultad para acreditar la comisión de este delito reside en conseguir demostrar los hechos, que no se podrán probar siempre, sobre todo cuando la agresión y la violencia se llevan a cabo tras las paredes de la vivienda conyugal. Muchas mujeres prefieren no denunciar pues la denuncia de la esposa contra su marido está mal vista por la sociedad con la consecuencia de un deterioro de la posición social de la mujer y de problemas económicos ya que es frecuente que la mujer no tenga un trabajo que le permita una independencia económica. A esto hay que añadir el insuficiente número de centros de acogida ${ }^{37}$, la existencia de un vacío legal y el miedo a la venganza del marido ${ }^{38}$.

condenado, el juez pronuncie una pena referida a otra categoría de infracción.»

${ }^{31}$ Art. 113 CPM: «La categoría de la infracción se modifica cuando por razón de circunstancias agravantes, la ley dicta una pena referida a otra categoría de infracción.»

${ }^{32}$ Art. 28 CPM: «La pena de prisión se ejecuta en uno de los establecimientos destinados a ello o en un módulo especial de un establecimiento central, con trabajo obligatorio en el interior y el exterior, salvo el caso de incapacidad física constatada.»

${ }_{33}$ Art. 24 CPM: «La pena de reclusión se ejecuta en un establecimiento central con aislamiento nocturno cuando la disposición del lugar lo permita y con trabajo obligatorio, salvo que haya una incapacidad física constatada.

En ningún caso, el condenado a reclusión puede ser admitido a trabajar en el exterior antes de haber cumplido diez años de su pena si ha sido condenado a cadena perpetua o el cuarto de la pena impuesta si ha sido condenado por tiempo determinado.»

${ }^{34}$ ABDELWAHID ALAMI MACHICHI: ob., cit., pág.309.

35 idem

${ }^{36}$ Art. 114 CPM: «Toda tentativa de crimen que ha sido manifestada por un comienzo de ejecución o por actos inequívocos tendentes directamente a cometerlo, si no ha sido suspendida o si no ha llegado a producir el resultado por circunstancias independientes de la voluntad del autor, es asimilada al crimen consumado y castigada como tal.»

${ }^{37}$ Según el Consejo Nacional de Derechos Humanos, Dawha, 28 de noviembre de 2011, Marruecos cuenta con tres centros de acogida para mujeres víctimas de violencia y cinco centros de acogida para madres solteras. Sin embargo la cantidad de células o unidades de apoyo moral y asesoramiento jurídico llegan a ser 350 distribuidas entre los tribunales y las asociaciones.

${ }^{38}$ LATIFA JOUHIR: ob., cit., pág. 11. 


\section{DRISS JEDDI HAOUKICH}

El bien jurídico protegido en el delito de lesiones o malos tratos es la salud física y la integridad corporal de la personas ${ }^{39}$. El Código penal marroquí no castiga el maltrato psicológico por lo que las lesiones a la salud psíquica quedan fuera del ámbito penal, aunque la Constitución marroquí vela por la integridad física y moral de las personas ${ }^{40}$.

Sujeto activo y pasivo de los malos tratos entre cónyuges solo pueden ser las personas ligadas por una relación matrimonial, hombre y mujer casados legalmente ${ }^{41}$, por lo que quedan fuera las parejas de hecho, ya sean heterosexuales o del mismo sexo, y las que han celebrado esponsales con una promesa mutua de matrimonio ${ }^{42}$. Sin embargo sí es posible en estos casos de los malos tratos aplicar el art. 404 CPM cuando la víctima es una mujer que está incluida expresamente como sujeto pasivo con independencia de la situación personal.

En la línea adoptada por el legislador marroquí para una mejor tutela de las mujeres frente a actos violentos, se exime de la obligación de mantener el secreto profesional, cuando denuncian ante la autoridad judicial o administrativa competente hechos de los que tienen conocimiento por el ejercicio de su profesión, a los médicos, cirujanos y oficiales de salud, así como a los farmacéuticos, comadronas $\mathrm{u}$ otras personas depositarias de secretos que les hayan sido confiados cuando atañen a hechos delictivos o actos de malos tratos que tengan como víctimas a menores de dieciocho años, una mujer o sea una agresión de un esposo contra el otro. Sin embargo, estos profesionales no están obligados a testificar en juicio ${ }^{43}$.

${ }^{39}$ ABOU EL MAATI HAFID / ABOU EL FOUTOUH: ob., cit., pág.133.

40 Art.22 CM: «No se puede atentar contra la integridad física o moral de cualquier persona, cualquiera que sea la circunstancia o por cualquier persona privada o pública. Nadie puede infligir a otro, bajo ningún pretexto, tratos crueles, inhumanos, degradantes o que afecten a la dignidad. La práctica de la tortura, bajo todas sus formas y por cualquiera, es un crimen castigado por la ley.»

${ }^{41}$ Art. 4 CFM: «El matrimonio es un pacto fundado en el consentimiento mutuo para establecer una unión legal y duradera, entre un hombre y una mujer. Tiene como finalidad la vida en la fidelidad recíproca, la pureza y la fundación de una familia estable bajo la dirección de los dos esposos, conforme a las disposiciones del presente Código.»

${ }^{42}$ Art.5 CFM: «Los esponsales son una promesa mutua de matrimonio entre un hombre y una mujer.

Los esponsales se realizan cuando ambas partes expresan, por cualquier medio admitido habitualmente, su promesa mutua de contraer matrimonio. Esto ocurre con la recitación de la Fatiha [primer Surat del Corán] y con las prácticas admitidas por los usos y costumbres en cuanto al intercambio de regalos.»

${ }^{43}$ Art. 446 CPM: «Los médicos, cirujanos u oficiales de salud, así como los farmacéuticos, las comadronas o cualquier persona depositarios, por estado o profesión o por funciones permanentes o temporales, de secretos que les han sido confiados que, fuera de los casos en que la ley obliga o les autoriza a denunciarlos, hayan revelado 
Como se aprecia en el cuadro, que a continuación se expone, la mujer también sufre agresiones por parte de personas que no son su cónyuge.

Relación del agresor con la víctima en los casos de malos tratos contra la mujer en Marruecos (2010) ${ }^{44}$

\begin{tabular}{lc}
\hline \multicolumn{1}{c}{ Tipo de Parentesco con la mujer } & Número de personas \\
\hline Personas ajenas de la familia & 10.665 \\
\hline Cónyuge & 7.079 \\
\hline Empleado de Hogar & 388 \\
\hline Madre & 212 \\
\hline Hermano & 175 \\
\hline Padre & 148 \\
\hline Jefe en el trabajo & 76 \\
\hline Hermana $\quad 54$ \\
\hline \multicolumn{1}{c}{ Total } & $\mathbf{1 8 . 7 9 7}$
\end{tabular}

Los 7.079 casos de violencia conyugal contra la mujer representan el importante porcentaje del 38\% siendo el tipo de violencia más extendida, mientras que los actos violentos cometidos por personas ajenas a la familia, con una mayor variedad de agresiones, constituye el $49 \%$.

El art. 404 CPM regula la comisión dolosa de las lesiones o malos tratos entre los cónyuges con independencia del motivo que los provoque, como la venganza, o la utilización de otra persona para cau$\operatorname{sarlas}^{45}$.

secretos, son castigados con prisión de un mes a seis meses y multa de mil doscientos a veinte mil dírhams.

Sin embargo, las personas enumeradas anteriormente no incurren en las penas previstas en el párrafo anterior:

Cuando, sin ser requeridas, denuncien los abortos de los que hayan tenido conocimiento con ocasión del ejercicio de su profesión o de sus funciones;

Cuando denuncien a las autoridades judiciales o administrativas competentes hechos delictivos o actos de malos tratos o de privaciones perpetrados contra menores de 18 años o por un esposo contra el otro o contra una mujer de los que hayan tenido conocimiento con ocasión del ejercicio de su profesión o de sus funciones.

Citadas ante la justicia por asuntos relativos a las infracciones arriba apuntadas las mencionadas personas son libres de aportar o no su testimonio.»

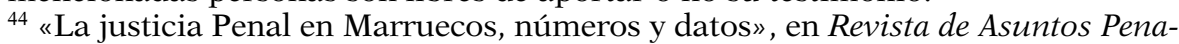
les, ob. cit., pág. 282

${ }^{45}$ ABDELWAHID ALAMI MACHICHI: ob., cit., pág.311. 


\section{DRISS JEDDI HAOUKICH}

\section{III.B. Penas}

De la modificación del art. 404 CPM por Ley 24.03 ha resultado un endurecimiento de las penas ${ }^{46}$ que se agravan respecto de las previstas en los arts. 400 a 403 CPM según el resultado producido lo que en algún caso da lugar incluso a un cambio en la categoría de la infracción ${ }^{47}$. La pena de prisión se cumple en establecimientos especiales o en un módulo de un presidio estatal central, con trabajo forzado en el interior o el exterior, salvo incapacidad física del penado ${ }^{48}$. La pena de reclusión se cumple en un presidio estatal central con aislamiento nocturno y con trabajo forzado en el interior; en caso de reclusión a perpetuidad el condenado puede realizar el trabajo forzado en el exterior después de haber cumplido diez años de su condena, que quedan reducidos al cuarto de la pena impuesta si la reclusión es por un tiempo limitado ${ }^{49}$.

No siempre se establece una pena accesoria de inhabilitación para el ejercicio de uno o más de los derechos cívicos, civiles o de familia como permite el art. $40 \mathrm{CPM}^{50}$ para los supuestos en los que la pena

${ }^{46}$ STS num.1168, causa penal 8627/11, de 27 de octubre de 2011, publicada en la Revista de la Jurisprudencia del Tribunal Supremo núm. 75, pág. 385:»Con la modificación del art. 404 CPM, el legislador endurece la pena prevista contra el cónyuge que cometa intencionalmente lesiones, agresiones, $\mathrm{u}$ otro tipo de violencia contra su cónyuge, y el Tribunal Penal ha de limitarse de duplicar la pena a la hora de pronunciarla, en los casos previstos en arts.400 y 401. Si el Tribunal otorga el cónyuge-autor las circunstancias atenuantes, o la suspensión de la pena, habrá de dar una justificación específica para ello.»

${ }^{47}$ Art. 111 CPM: «Las infracciones son calificadas como crimen, delito correccional, delito de policía y contravención:

La infracción que la ley castiga con una de las penas previstas en el artículo 16 es un crimen;

La infracción que la ley castiga con una pena de prisión cuyo máximo está fijado en más de dos años es un delito correccional;

La infracción que la ley castiga con una pena de prisión cuyo está fijado en dos años o menos de dos años, o con una multa de más de 200 dirhams es un delito de policía;

La infracción que la ley castiga con una de las penas previstas en el artículo 18 es una contravención.»

Las penas del art. 16 CPM son la muerte, la reclusión perpetua, la reclusión temporal por una duración de cinco a treinta años, la residencia forzosa y la degradación cívica. Las penas del art. 18 CPM son la detención por menos de un mes y la multa de 30 a 1.200 dirhams. El art. 17 CPM establece que la pena de prisión de entre un mes y cinco años es una pena delictual, lo que la distingue de las penas criminales del art. 16 CPM y de las penas contravencionales del art. 18 CPM.

${ }^{48}$ Art. 28 CPM

${ }^{49}$ Art. $24 \mathrm{CPM}$

${ }^{50}$ Art. 40 CPM: «Cuando pronuncien una pena delictual, los tribunales pueden, en los casos determinados por la ley y por una duración de uno a diez años, prohibir al condenado el ejercicio de uno varios de los derechos cívicos, civiles o de familia previstos en el artículo 26.» 


\section{La violencia conyugal en el Código Penal de Marruecos}

sea de la categoría de pena delictual (delito correccional o delito de policía). La interdicción legal y la degradación cívica se aplican de pleno derecho cuando los hechos son calificados como crimen ${ }^{51}$.

En cuanto al decomiso, según la categoría de infracción, se atiene a las reglas siguientes: el juez puede decretarlo cuando el hecho delictivo es calificado como un crimen $^{52}$, sin embargo cuando es calificado como un delito correccional o de policía únicamente puede decretarlo en los casos expresamente previstos por la ley ${ }^{53}$.

Si ambos cónyuges fueran condenados simultáneamente por haberse agredido mutuamente se aplican las reglas siguientes. La mujer embarazada de más de seis meses comenzará a cumplir su condena cuarenta días después del parto, y si ha dado a luz antes de los cuarenta días de la fecha de comienzo de su condena la ejecución de la pena será diferida ${ }^{54}$. Cuando ambos cónyuges son condenados ${ }^{55}$ a una pena de prisión inferior a un año, y no están detenidos en el momento

${ }^{51}$ Art. 37 CPM: «La interdicción legal y la degradación cívica cuando es accesoria solo se une a las penas criminales.

No se tienen que ser pronunciadas y se aplican de pleno derecho.»

Art. 38 CPM: «La interdicción legal priva al condenado del ejercicio de sus derechos patrimoniales durante la ejecución de la pena principal.

Sin embargo, tiene el derecho de escoger un mandatario para que le represente en el ejercicio de sus derechos, bajo el control del tutor designado conforme a las prescripciones del artículo siguiente.»

${ }^{52}$ Art. 43 CPM: «En caso de condena por un hecho calificado como crimen, el juez puede ordenar la confiscación, en provecho del Estado, bajo reserva de los derechos de terceros, le los objetos y cosas que han servido o deberían haber servido a la infracción, o que son sus productos, así como las dádivas u otros beneficios que han servido o deberían haber servido a recompensar al autor de la infracción.»

${ }^{53}$ Art. 44 CPM: «En los casos de condena por hechos calificados como delitos o contravenciones, el juez solo puede ordenar la confiscación en los casos previstos expresamente por la ley.»

${ }^{54}$ Art. 32 CPM: «Si se comprueba que una mujer condenada a una pena privativa de libertad está embarazada de más de seis meses, no comenzará su pena hasta cuarenta días después de su parto. Si ya está encarcelada, se beneficiará, durante el tiempo necesario, del régimen de la detención preventiva:

Se difiere la ejecución de las penas privativas de libertad para las mujeres que han dado a luz menos de cuarenta días antes de su condena.»

${ }_{55}$ Art. 33 CPM: «El marido y la mujer condenados, aún por infracciones diferentes, a una pena de prisión inferior a un año y no detenidos el día del juicio, no ejecutan simultáneamente sus penas, si, justificando un domicilio cierto, tienen a su cargo y bajo su protección, un menor de menos de dieciocho años que no puede ser acogido en condiciones satisfactorias por una persona pública o privada salvo petición en contra por su parte.

Cuando la pena de prisión pronunciada contra cada cónyuge es superior a un año, y si tienen a su cargo o bajo su protección a un menor de de menos de dieciocho años o si el menor no puede ser acogido por los miembros de su familia o por una persona pública o privada, en condiciones satisfactorias, son aplicables las disposiciones de la ley relativa al procedimiento penal sobre la protección de los menores en 


\section{DRISS JEDDI HAOUKICH}

del juicio, la pena no se cumple simultáneamente siempre que acrediten un domicilio conocido y que tengan a su cargo o bajo a su protección a un menor de dieciocho años que no pueda ser acogido adecuadamente por una persona pública o privada. En el mismo caso con una pena superior a un año los cónyuges pueden cumplir la pena simultáneamente y se aplican para la protección del menor las disposiciones previstas en la ley de procedimiento penal para menores en situación difícil ${ }^{56} \mathrm{o}$ las disposiciones de la kafala.

Según el art. 404.1. ${ }^{\circ}$ CPM los actos violentos que conlleven los resultados de los arts. 400 y 401 CPM han de ser castigados con el doble de la pena prevista en estos. La consecuencia es que la producción de una enfermedad o una incapacidad para el trabajo durante menos de veinte días (art. 400 primer párrafo CPM) eleva la pena a prisión de dos meses a dos años y multa de 400 a 1.000 dirhams o una sola de estas penas, lo que no modifica la categoría de la infracción que continúa siendo un delito de policía. Pero si las agresiones se han producido con premeditación o alevosía o empleando un arma (segundo párrafo del art. $400 \mathrm{CPM}$ ) la pena se eleva a prisión de uno a cuatro años y multa de 400 a 2.000 dirhams, pasando de ser un delito de policía a un delito correccional. Si el resultado es una incapacidad superior a veinte días (art. $401 \mathrm{CPM}$ ), la pena es de dos a seis años de prisión y multa de 400 a 2.000 dirhams; la premeditación, la alevosía o el uso de un arma eleva la pena a prisión de cuatro a diez años y multa de 500 a 4.000 dirhams $^{57}$; siendo el culpable condenado además por un plazo de entre cinco y diez años con la inhabilitación de los derechos mencionados en el art. 40 CPM y la prohibición de residencia.

$\mathrm{El}$ art. 404.2. ${ }^{\circ} \mathrm{CPM}$ establece una pena de reclusión de diez a veinte años cuando se produzca una mutilación, una amputación o privación del uso de un miembro, la ceguera, la pérdida de un ojo o cualquier enfermedad permanente (primer párrafo del art. $402 \mathrm{CPM}$ ). Si se ha actuado con premeditación o alevosía o empleado un arma (segundo párrafo del art. 402 CPM) la pena se eleva a la reclusión de veinte a treinta años.

El apartado 3. ${ }^{\circ}$ del art. $404 \mathrm{CPM}$ castiga con reclusión de veinte a treinta años la muerte preterintencional de la víctima cuando se produce a causa de agresiones violentas voluntarias (primer párrafo del

\footnotetext{
situación difícil o las disposiciones de la kafala de los niños abandonados, cuando reúnen las condiciones exigidas.»

${ }^{56}$ Arts. 512 a 517 de la Ley 22.01.

${ }^{57}$ Art.113: «La categoría de la infracción se modifica cuando, en base a circunstancias agravantes, la ley ordena una pena relativa a otra categoría de infracción.»
} 
art. 403 CPM); la reclusión perpetua se aplica cuando los hechos violentos se realizan con premeditación o alevosía o el uso de armas.

$\mathrm{El}$ art. 146 CPM permite al juez rebajar la pena cuando en su opinión, en el caso concreto que le es sometido, la pena es excesiva respecto de la gravedad de los hechos o la culpabilidad del autor. Solo tiene que motivar especialmente la sentencia sobre esta cuestión. La reclusión perpetua se reduce a reclusión de diez a treinta años, la reclusión de veinte a treinta años pasa a reclusión de cinco a veinte años, si la pena criminal está acompañada de una multa esta se puede reducir hasta 120 dirhams o suprimirse, la residencia forzosa es sustituida por la degradación cívica o la prisión de seis mese a dos años y la degradación se sustituye por una pena de prisión de seis mese a dos años o la privación de algunos de los derechos previstos en el art. 26 CPM. En virtud del art. 149 CPM, en los delitos correccionales, aun en caso de reincidencia, cuando la pena es de prisión y multa o solo una de estas penas el juez puede reducir la pena por debajo del mínimo establecido sin que en ningún caso la prisión sea inferior a un mes o la multa a 120 dirhams.

El concurso de crímenes o delitos ${ }^{58}$ juzgados simultáneamente en la misma jurisdicción se castiga con una sola pena privativa de libertad cuya duración no puede ser mayor que la prevista por la ley para la infracción más grave. Si hay varios procedimientos en los que se pronuncian varias penas privativas de libertad solo se ejecuta la pena más grave. Si las penas impuestas son de la misma naturaleza, el juez motivándolo puede ordenar la acumulación de todas o de parte de ellas con el límite del máximo previsto por la ley para la pena más grave. Salvo que el juez decida expresamente otra cosa las penas pecuniarias se acumulan así como las penas accesorias.

\section{III.C. Tentativa y participación}

La tentativa de un crimen manifestada por un principio de ejecución o mediante actos inequívocos dirigidos directamente a cometerlo, si no ha sido suspendida o no ha conseguido su objetivo por circunstancias ajenas al autor se asimila a la consumación y es castigada como tal ${ }^{59}$. La tentativa de un delito solo se castiga cuando está expresamente prevista por la ley ${ }^{60}$. Por lo tanto, solo cuando se producen

\footnotetext{
${ }^{58}$ Arts. 119 a 122 CPM

${ }^{59}$ Art. 114 CPM

${ }^{60}$ Art. 115 CPM
} 


\section{DRISS JEDDI HAOUKICH}

los resultados tipificados en los arts. 402 y 403 CPM la tentativa de maltrato conyugal está castigada.

Si la lesión causa la muerte por imprudencia la tentativa no será posible por la ausencia de la intención delictiva. Pero se plantea un caso discutible, cuando el autor del delito tuvo la intención delictiva de causar una amputación permanente y, sin embargo, algunas causas ajenas de su voluntad le han impedido a ejecutar su intención delictiva por lo que no acabó la ejecución del delito ${ }^{61}$.

Son coautores los que personalmente participan personalmente en la ejecución material de la infracción ${ }^{62}$. La complicidad solo se castiga en los crímenes y delitos. Se define en el art. 129 CPM como la participación no directa en la infracción con una serie de actos tasados ${ }^{63}$. Está castigada con la misma pena que la autoría. Las circunstancias personales que agravan, atenúan o eximen de pena solo tienen efecto en las personas a las que se refieren. Las circunstancias objetivas inherentes a la infracción que agravan o disminuyen la pena afectan a todos los partícipes incluso si las desconocen ${ }^{64}$.

\section{III.D. La dificultad de acreditar el delito de malos tratos entre cónyuges}

El principio de prueba adoptado por el Código de Procedimiento penal marroquí 65 es un logro legal. Su aplicación en el ámbito penal, está supeditado a una filosofía, estructura y disposiciones que no dan a la violencia contra la mujer un trato adecuado, lo que conduce a

${ }^{61}$ AHMED EL KHAMLICHI: ob., cit., págs.131 y ss.

${ }^{62}$ Art. 128 CPM

${ }^{63}$ Art. 129 CPM: «Son considerados como cómplices de una infracción calificada como crimen o delito los que, sin participación directa en esta infracción, han:

1. ${ }^{\circ}$ Por dones, promesas, amenazas, abuso de autoridad o de poder, maquinaciones o artificios culpables, provocado a esta acción o ha dado instrucciones para cometerla;

2. ${ }^{\circ}$ Procurado armas, instrumentos o cualquier otro medio que hubiera servido a la acción sabiendo que iban a servir;

3. ${ }^{\circ}$ Con conocimiento, ayudado o asistido al autor o a las autores de la acción, en los hechos que la han preparado o facilitado;

4. ${ }^{\circ}$ Con conocimiento de su conducta criminal, habitualmente dado alojamiento, lugar de retiro o de reunión a uno o varios malhechores que ejerzan bandidaje o violencias contra la seguridad del Estado, la paz pública, las personas o las propiedades.

La complicidad no es punible en materia de contravención.»

${ }^{64}$ Art. 130 CPM

${ }^{65}$ Art. 288 CPPM:»Excepto los casos en que la ley disponga otra cosa, las infracciones pueden acreditarse mediante todo tipo de pruebas y el juez decide según su íntima convicción.» 


\section{La violencia conyugal en el Código Penal de Marruecos}

que a veces se consiga eludir el castigo. Se presentan los siguientes problemas en la prueba:

a) A veces se excluyen medios de prueba como los certificados médicos o radiografías, porque falta acreditar la relación de causalidad entre el daño y el causante del mismo.

b) Los tribunales se basan en las declaraciones del denunciado ante la policía judicial, recogidas en un atestado que se constituye como una prueba determinante para dictar una sentencia absolutoria $^{66}$, sobre todo en los casos en que el denunciado niega los hechos y se añade la ausencia de pruebas sólidas que contradigan la negación del denunciado.

c) Para los jueces existe una jerarquía en los tipos de prueba. La mayoría de las veces el juez constituye su convicción en base a pruebas fuertes como la declaración de los testigos, sabiendo que es característico de esta violencia contra las mujeres su comisión en lugares cerrados, como el domicilio conyugal o lugares aislados. El 96\% de la violencia contra la mujer se comete dentro del domicilio y el $4 \%$ de esa violencia se comete fuera del domicilio ${ }^{67}$; el $83 \%$ de las víctimas son mujeres casadas y el $17 \%$ son divorciadas ${ }^{68}$.

Aunque la violencia conyugal está tipificada en el art. 404 CPM la realidad es que los tribunales sólo la persiguen cuando está asociada a otros tipos delictivos. Así, si se consigue implicar al marido como autor de los malos tratos las sentencias pronuncian la suspensión de la pena de prisión cuando no absuelven por falta de pruebas, lo que es muy frecuente como se puede apreciar en la jurisprudencia de los Tribunales de Primera Instancia ${ }^{69}$. Estos pronunciamientos judiciales van en contra de la voluntad del legislador que ha optado por la criminalización de la violencia conyugal y la imposición de penas graves para

${ }^{66}$ Art.291 CPPM:»Los atestados verbales y los informes redactados por la policía judicial y los militares de la gendarmería para constatar los delitos y las contravenciones dan fe salvo prueba en contra.»

${ }^{67}$ LATIFA JOUHIR: ob. cit., pág. 49

${ }^{68}$ idem, pág. 53

${ }^{69}$ Sentencia Tribunal de Primera Instancia de Fes, de 14 de abril de 2005: condena a un mes de prisión que se suspende y una multa de 500 dirhams. Sentencia Tribunal de Primera Instancia de Beni Mellal, de 9 de diciembre de 2005: condena a dos meses de prisión que suspende y una multa de 500 dirhams.

KHADIJA EL FILALI ALACH: La violence envers la femme au Maroc quelle protection, la violence conjugale comme exemple, mémoire de DESA, Université Mohamed ben Abdellah, Faculté de droit, Fés, 2005-2006, pág. 95. 


\section{DRISS JEDDI HAOUKICH}

luchar contra los maltratadores, proporcionando a los jueces herramientas contra esta lacra social ${ }^{70}$.

Se puede concluir que la interpretación de la regla de la libre apreciación de la prueba y su aplicación, sin tener en cuenta las particularidades de la violencia cometida contra la mujer, su naturaleza, su espacio, en definitiva su dificultad de prueba, causa una discriminación real. La libertad en la apreciación de la prueba se convierte en una limitación de prueba con la consecuente elusión del castigo por parte del agresor.

\section{DERECHO COMPARADO}

A continuación se resume brevemente la protección penal que ofrecen algunos países del entorno mediterráneo a las mujeres frente a la violencia conyugal. Por un lado, se ha elegido España y Francia como países de la orilla europea que han tenido históricamente influencia en la legislación marroquí. Por otro, Argelia y Túnez son países culturalmente próximos a Marruecos.

\section{a) España}

En España la Ley Orgánica 1/2004 de Medidas de Protección Integral contra la Violencia de Género tiene por objeto actuar contra esta violencia desde varios ámbitos. Su finalidad es prevenirla, sancionarla y erradicarla así como prestar asistencia a las víctimas. Define la violencia de género como «todo acto de violencia física y psicológica, incluida las agresiones a la libertad sexual, las amenazas, las coacciones o la privación arbitraria de libertad» cometido sobre las mujeres por hombres que sean o hayan sido sus cónyuges o que estén o hayan estado ligados a ellas por relaciones similares de afectividad, aun sin convivencia.

España elaboró un Plan Nacional de Sensibilización y Prevención de la violencia de género (2007-2008) que se ha continuado con diversos planes de atención y prevención de la violencia de género así como varios protocolos de actuación de los profesionales que interviene en este ámbito ${ }^{71}$.

${ }^{70}$ MOHAMED CHAHIB: «La situation de la femme dans le doit pénal marocain quelle protection?», en Lecturas en materia penal, num.17, Supervisión MOHAMED OUZIAN, segunda parte, edit. Maarif, Rabat, 2014, pág. 287

${ }^{71}$ Protocolo de coordinación entre los órdenes jurisdiccionales penal y civil, Protocolo de actuación de las Fuerzas y Cuerpos de Seguridad y de coordinación con los órganos judiciales para la protección de las víctimas de violencia doméstica y de género, Protocolo para la implantación de la orden de protección de las víctimas de violencia doméstica, Protocolo común para la actuación sanitaria ante la violencia de 


\section{La violencia conyugal en el Código Penal de Marruecos}

En el Código penal existen tipos específicos para sancionar la violencia de género física y psíquica en los delitos de lesiones, maltrato puntual y habitual, amenazas o coacciones ${ }^{72}$.

\section{b) Francia}

En la legislación francesa la expresión «violencia contra la mujer» tiene un significado amplio que engloba los actos de violencia dirigidos contra las personas de sexo femenino ya sea en la vida pública o privada, siguiendo la definición dada por la Convención para la eliminación de todas las formas de discriminación contra la mujer ${ }^{73}$. En cuanto a la violencia doméstica, el concepto se aplica tanto a la violencia entre cónyuges como a la que acaece entre parejas de hecho. Para prevenir y penalizar la violencia de género, en Francia se han elaborado cuatro planes interministeriales trienales para prevenir y luchar contra las violencias hechas a las mujeres y se han aprobado diversas disposiciones legislativas. El primer plan (2005-2007) ${ }^{74}$ se denominó «10 medidas para la autonomía de las mujeres». El segundo plan (2008-2010) ${ }^{75}$ se titulaba $" 12$ objetivos para combatir la violencia contra la mujer» ${ }^{76}$. El tercer plan $(2011-2013)^{77}$ se centró en la violencia intrafamiliar, los matrimonios forzados, el acoso sexista y sexual en el trabajo, la violación y las agresiones sexuales así como la relación entre la prostitución y la trata de seres humanos. El cuarto plan (2014-2016) ${ }^{78}$ reconoce que el anterior plan era muy ambicioso, y que no se han llegado a cumplir los objetivos, por lo que se centra sobre un pequeño número de prioridades, siendo una de ellas no dejar sin respuesta penal y social cualquier violencia denunciada.

Aunque Francia no tiene una ley general sobre la violencia de género ${ }^{79}$, en el Código penal existe una previsión de agravación de la pena cuando el homicidio doloso tiene como víctima al cónyuge, con-

género, Protocolo para la valoración policial del nivel de riesgo de violencia contra la mujer en los supuestos de la Ley Orgánica 1/2004 y su comunicación a los órganos judiciales y al Ministerio Fiscal.

72 Arts. 148, 150,153, 171, 172, 173 CP España

${ }^{73}$ FRANCOIS DIEU / PASCAL SUHARD: Justice et femme battue, edit. L'Armattan, Paris 2008, págs.15 y ss.

${ }^{74}$ www.social-sante.gouv.fr/IMG/pdf/planviolences.pdf

${ }^{75} \mathrm{http}: / /$ travail-emploi.gouv.fr/IMG/pdf/Plan_VL-2.pdf

${ }^{76}$ FRANCOIS DIEU / PASCAL SUHARD: ob. cit., pág.16

$77 \mathrm{http} / / /$ www.stop-violences-femmes.gouv.fr/IMG/pdf/Plan_de_lutte_contre_les_ violences_2011-2013.pdf

${ }^{78} \mathrm{http} / / / \mathrm{femmes}$.gouv.fr/wp-content/uploads/2013/11/4e-planVFF_22112013.pdf

79 JOSE ALBERTO MAGARIÑOS YÁNEZ: El derecho contra la violencia de género. Análisis de la respuesta del ordenamiento jurídico internacional, comunitario, compa- 


\section{DRISS JEDDI HAOUKICH}

cubino o pareja ${ }^{80}$ y en los atentados dolosos contra la integridad física y psíquica de las personas ${ }^{81}$.

\section{c) Argelia}

El Código penal argelino entre los delitos de lesiones solo tiene una referencia específica a los cónyuges cuando la lesión se produce por envenenamiento. En el resto de los delitos violentos no existe ninguna referencia a la relación conyugal, salvo para atenuar la pena cuando la muerte, las lesiones o los golpes tienen como víctima al cónyuge o su cómplice sorprendidos en el acto de flagrante delito de adulterio $^{82}$.

En el delito de envenenamiento la pena se modula en proporción a la gravedad de los daños causados o la muerte. La administración dolosa, sin intención de causar la muerte, de sustancias peligrosas para la salud se sanciona con prisión de dos a cinco años si resulta una enfermedad o incapacidad laboral. La pena se eleva a la reclusión de cinco a diez años si la enfermedad o incapacidad laboral es por un tiempo superior a los quince días. Cuando se causa una enfermedad incurable la pena es de reclusión de diez a veinte años. Si se produce la muerte preterintencional la pena es de reclusión perpetua. Además, en todos los casos, se puede imponer la prohibición de acudir a determinados lugares o la prohibición de residencia.

\section{d) Túnez}

El artículo 218 del Código penal tunecino ${ }^{83}$ prevé una pena agravada, de dos años de prisión y dos mil dinares de multa, para el cón-

rado, español y autonómico. Enfoque multidisciplinar del problema, edit. Montecorvo, Madrid, 2007, pág. 54.

${ }^{80}$ Art. 221-4 CP Francia

${ }^{81}$ Arts. 222-3, 222-8, 222-10, 222-12, 222-13, 222-14, 222-18-3, 222-28, 222-24, 222-33-2-1 CP Francia

${ }^{82}$ Art. 279 CP Argelia: « Le meurtre, les blessures et les coups sont excusables, s'ils sont commis par l'un des époux sur son conjoint ainsi que sur le complice à l'instant où il les surprend en flagrant délit d'adultère. "

${ }^{83}$ Art. 218 CP Túnez: «Tout individu qui, volontairement, fait des blessures, porte des coups, ou commet toute autre violence ou voie de fait ne rentrant pas dans les prévisions de l'article 319, est puni d'un emprisonnement d'un an et d'une amende de mille dinars.

Si l'auteur de l'agression est un descendant ou conjoint de la victime, la peine est de deux ans d'emprisonnement et de deux mille dinars d'amende. 


\section{La violencia conyugal en el Código Penal de Marruecos}

yuge que inflige voluntariamente lesiones, golpes $\mathrm{u}$ otras violencias que no ocasionen daños graves (serios y durables). Con la misma pena se castiga la tentativa. Sin embargo, esta causa de agravación no se contempla cuando los hechos se producen con premeditación o el resultado es la mutilación, la pérdida del uso de un miembro, la deformidad, la enfermedad o la incapacidad permanente ${ }^{84}$.

\section{LA LEY ISLÁMICA Y LA VIOLENCIA SOBRE LA MUJER}

La ley Islámica aconseja a los musulmanes que traten bien a las mujeres en todos los aspectos de la vida. Dice el versículo 19 del Surat Las mujeres: «Los mejores de entre vosotros son los que mejor tratan a las mujeres» ${ }^{85}$. La mujer tiene derecho a pedir la separación y el divorcio cuando el marido la maltrata causándole daño ${ }^{86}$, aunque debe ser como último recurso pues «de lo lícito, el divorcio es lo más odioso para Dios» ${ }^{87}$.

El Profeta prohibió expresamente que los maridos pegaran a sus mujeres diciendo «Ninguno de vosotros debe golpear a su mujer como si fuera un esclavo y luego tener relaciones con ella al final del día ${ }^{88}$. En El Corán existe un versículo que ha creado una cierta polémica en su interpretación: «Los hombres tienen autoridad sobre las mujeres en virtud de la preferencia que Alá ha dado a unos más que a otros y de los bienes que gastan. Las mujeres virtuosas son devotas y

S'il y a eu préméditation, la peine est de trois ans d'emprisonnement et de trois mille dinars d'amende.

Le désistement de l'ascendant ou du conjoint victimes, arrête les poursuites, le procès, ou l'exécution de la peine.

La tentative est punissable. »

${ }^{84}$ Art.219 CP Túnez: «Quand les violences ci-dessus exprimées ont été suivies de mutilation, perte de l'usage d'un membre, défiguration, infirmité ou incapacité permanente dont le taux ne dépasse pas $20 \%$, le coupable est puni de cinq ans d'emprisonnement.

La peine sera de dix ans de prison, s'il est résulté de ces sortes de violence une incapacité dont le taux dépasse $20 \%$.

La peine est portée à douze ans d'emprisonnement si le coupable est un descendant de la victime, quel que soit le taux de l'incapacité, même en cas de désistement.»

${ }^{85}$ Surat Las mujeres, versículo 129: "Y no podréis ser completamente equitativos con las mujeres aunque queráis. Sin embargo, no inclinéis demasiado vuestras preferencias con una sobre otra de forma que una se quede descolgada. Y si arregláis vuestros asuntos con justicia y sois temerosos, Allah es Perdonador y Misericordioso.»

${ }^{86}$ MUHAMAD SAYYAH MESNED ALESA: El estatus de la mujer en la sociedad Arabo-Islámico medieval entre oriente y occidente, Tesis Doctoral, Universidad de Granada 2007, pág. 97

87 idem

${ }^{88}$ Citado por AHMAD AL BUJARI: http://www.nurelislam.com/licito/cap3-4.html 


\section{DRISS JEDDI HAOUKICH}

cuidan, en ausencia de sus maridos, de lo que Allah manda que cuiden. ¡Amonestad a aquéllas de quienes temáis que se rebelen, dejadlas solas en el lecho, pegadles! Si os obedecen, no os metáis más con ellas. Alá es excelso, grande» ${ }^{89}$. En este versículo Dios habla del caso de una esposa que es inmoral y no respeta los derechos de su esposo. El trato en estos casos tan sensibles debe ser en etapas como vemos en el versículo. El remedio para tratar a una esposa de carácter censurable e inmoral debe hacerse gradualmente en tres etapas ${ }^{90}$ :

- Primera etapa: La etapa del consejo, la orientación y la advertencia sobre el castigo de Dios. El esposo debe recordar a su mujer la importancia de proteger sus derechos en el Islam. Esta es una etapa sencilla y tranquila, pero si este trato no resulta efectivo, entonces se debe pasar a la segunda etapa.

- Segunda etapa: No dormir con su esposa, o dormir con ella en la misma cama pero dándole la espalda, sin tocarla ni hablar con ella, ni tener relaciones sexuales. Esta etapa combina la rigurosidad y la bondad al mismo tiempo, a pesar de lo difícil de esta combinación. Pero si esto no funciona, sigue la tercera etapa de disciplina.

- Tercera y última etapa: Darle una palmada sin lastimarla ni dejarle marcas en su cuerpo, evitando dañar su rostro u otras partes sensibles. Este caso es aplicable como último recurso y debe entenderse a modo de corrección y no como represalia o para lastimarla.

La ley Islámica prohíbe golpear a las mujeres y advierte estrictamente sobre ello ${ }^{91}$. La mujer es físicamente más débil que el hombre y de menor resistencia y normalmente es incapaz de defenderse de la violencia $^{92}$. A pesar de que golpear a la mujer está prohibido como regla general, el Islam permite aleccionar a las esposas en un sentido muy restringido y limitado y sólo como último recurso y por un motivo válido ${ }^{93}$. Abundan las enseñanzas islámicas que demuestran repugnancia hacia las costumbres violentas contra la mujer. Precisamente, la tortura no está permitida ni con los peores enemigos. La ira y el daño psicológico es un comportamiento morboso que arruinaría cualquier relación conyugal y es ilícito e inaceptable desde cualquier pun-

${ }^{89}$ Surat An-Nisá, versículo 34

${ }^{90}$ ABDUL-RAHMAN AL SHEHA: La mujer en Islam: refutando los prejuicios más comunes, págs. 81 y s. http://islamhouse.com/es/books/273052/

${ }^{91}$ Surat An-Nisá, versículo 34

${ }^{92}$ Surat An-Nisá, versículo 231 «Retenerlas como es debido o dejarlas en libertad. No las sujetéis por la fuerza ni en violación. Quien hace esto es injusto consigo mismo».

${ }_{93}$ ABDUL-RAHMAN AL-SHEHA: ob. cit., pág. 81. 
to de vista. Las recomendaciones, consejos y ejemplo del Profeta durante toda su vida fueron en dirección opuesta a estas perversas inclinaciones y El Corán dice ${ }^{94}$ : «Convivid con ellas con benevolencia y justicia, y, si os disgustan, tal vez os esté disgustando algo en lo que Allah ha puesto mucho bien ${ }^{95}$.

\section{CONCLUSIONES}

El Reino de Marruecos, después de la ratificación de la Convención sobre la Eliminación de todas las Formas de Discriminación contra la Mujer (CEDAW), fue requerido para activar las reglas que garantizan la igualdad en el ámbito del Derecho penal en virtud del artículo 2 de la Convención que estipula que los Estados miembros se comprometen «a derogar todas las disposiciones penales nacionales que constituyan discriminación contra la mujer».

Constituye un progreso muy importante que el legislador en 2004 haya penalizado expresamente el delito de lesiones entre los cónyuges. Antes de esta modificación no existía ninguna norma sobre el delito de lesiones contra el cónyuge, había un vacío legislativo para penalizar estos actos de violencia contra la mujer.

El actual Código Penal abarca una amplia gama de delitos en los que la violencia penalizada no es la violencia basada en el género sino la violencia en general, sin importar el autor y la víctima, lo que refleja la ausencia de un tratamiento específico para proteger la mujer frente a este tipo de agresiones ${ }^{96}$. Tampoco incluye todas las formas de violencia, como la violencia psicológica y sexual o la violencia en ámbito familiar.

El art. 404 CPM trata por igual la violencia contra las mujeres y contra los hombres, sin tomar en cuenta las características y especialidades de la violencia contra las mujeres con sus diferencias en cuanto a su naturaleza, sus causas y sus efectos respecto de otras formas de violencia. Según un estudio realizado por el Consejo Nacional de Derecho Humanos, bajo el título «La experiencia Marroquí, en el ámbito de la lucha contra la violencia, logros y desafíos» celebrado en

${ }^{94}$ YARATULLAH MONTURIOL: Islam y Derecho Humanos, ed. Junta islámica, Córdoba 2009, pág. 70

${ }_{95}$ Surat An-Nisá, versículo 19

${ }^{96}$ En Marruecos el hogar familiar lleva el protagonismo 3.7 Millones (55\%) de las mujeres, sufren la violencia en ámbito de la vida conyugal, véase estudio sobre la violencia en Marruecos, estadística y números, Reino de Marruecos, Consejo nacional de Derechos Humanos, 28 de noviembre de 2011. 


\section{DRISS JEDDI HAOUKICH}

Daouha el 28 de noviembre de 2011, más de 62,8\% de la mujeres han sufrido alguna forma de violencia ${ }^{97}$. La mayoría de las agresiones se producen en la intimidad del hogar, donde el agresor puede actuar con casi total impunidad ${ }^{98}$, lo que dificulta presentar una denuncia y luego probar los hechos ${ }^{99}$. La aplicación de la regla de libertad de interpretación de la prueba sin observancia de las particularidades de los actos violentos cometidos contra la mujer, su naturaleza, su espacio, su dificultad, causa una discriminación real y la libertad de prueba se convierte en una limitación de prueba que con demasiada frecuencia lleva a la impunidad del autor. El delito de lesiones entre los cónyuges es perseguible de oficio, sin que necesidad de la previa denuncia de la persona ofendida, pero en la práctica su persecución está sujeta a esta denuncia.

A pesar de que aun no existe una ley especial para combatir la violencia contra la mujer a semejanza de la Ley Orgánica 1/2004 española, actualmente en Marruecos se está trabajando en un proyecto de Ley contra la violencia de género que endurecerá las sanciones con el fin de luchar contra esta lacra social ${ }^{100}$.

El progreso legislativo conquistado por Marruecos es importante pero todavía existen discriminaciones hacia la mujer marroquí como una tarea pendiente ${ }^{101}$. La violencia contra las mujeres está muy extendida, incluso en los países más desarrollados y democráticos. Las leyes por si mismas no son suficientes para poner fin a este lacra social en la que tiene mucho que ver la educación y el comportamiento

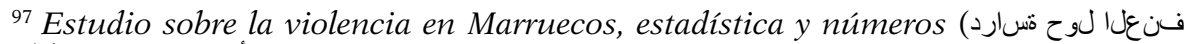

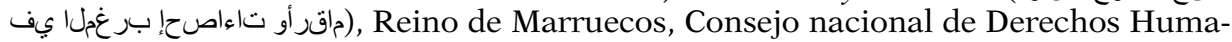
nos, 28 de noviembre de 2011: de los 9,5 millones de mujeres de entre 18 y 64 años de edad aproximadamente 6 millones de ellas ( 62,8 por ciento), han sufrido alguna forma de violencia durante los últimos 12 meses (3,8 millones de mujeres de las zonas urbanas y 2,2 millones en las zonas rurales).

${ }^{98}$ Según las estadística 96\% de los casos de la violencia se cometen dentro del domicilio conyugal, y $4 \%$ fuera de él (en el trabajo, en la calle...), véase LATIFA JOUHIR: ob. cit., pág. 49.

${ }^{99}$ La eficacia del Derecho penal en la protección de la mujer contra la violencia, no está relacionada con sus disposiciones penalizadoras y sobre los testimonios. Uno de los más graves problemas que se plantean en la aplicación del Código penal es la gran discrecionalidad que tienen los jueces para apreciar las circunstancias agravantes o atenuantes.

${ }^{100}$ El gobierno de Marruecos está preparando un nuevo proyecto de ley (Proyecto de Ley 103.13) para luchar contra la violencia de género. A pesar de que uno de los puntos más significativos de la Constitución de 2011 fue el reconocimiento de la igualdad entre hombres y mujeres, esta es aún un reto en el reino alauita donde es visible la discriminación en los ámbitos económico, social, educativo o laboral.

${ }^{101}$ MOHAMED CHAHIB: ob. cit., pág. 287. 
de cada uno, por eso la sensibilización de la sociedad y la labor de prevención con la ayuda de leyes eficaces podrán disminuir la violencia de género. A veces las leyes solas, aunque sean buenas, no alcanzan el objetivo deseado. 
